\title{
Children's Immunology, what can we learn from animal studies (1): \\ Decidual cells induce specific immune system of feto-maternal interface
}

\author{
Orie Nakamura \\ Osaka Medical Center and Research Institute for Maternal and Child Health, 840 Murodo-cho. Izumi, \\ Osaka 594-1101, Japan
}

(Received February 17, 2009)

\begin{abstract}
In mammals, pregnancy has very interesting interaction between the maternal uterus and the fetus. For maternal immune system, fetus is recognized as semiallograft. However the maternal immune cells do not attack and reject a fetus during a pregnant period. The reason why that immune tolerance is established in the maternal decidua is the specific area defined as the feto-maternal interface. While, if maternal immune cells recognize fetus as the not-self, the maternal immune cells will try to reject fetus, and then abortion will occur. For example, in a human, one of the reasons why the habitual abortion is understood as the failure of the maternal immune system. The extravillous cytotrophoblast are not attacked by the maternal immune cells, although that trophoblasts might reach even the myometrium. Exceeding the maternal myometrium doesn't decide the invasion of extravillous cytotrophoblast on the other hand. This suggests that proliferation in decidua be strictly adjusted. In human and mice, the maternal immune cells recognize the fetus trophoblasts. To escape from attack of lymphocytes, villous trophoblasts do not express classical major histocompatibility complex (MHC) class I molecules. But, in a human, extravillous trophoblasts express MHC-class I molecules such as human leukocyte antigen (HLA)-C, HLA-E and HLA-G, which are specific ligands for uterine NK (uNK) cells. In the decidua, various lymphocytes including T-cells, Tregs, macrophages, and uNK cells exist. Each immunocytes are not identified on their function, compose network with the decidual cells under progesterone existence, and interact with the success of pregnancy.
\end{abstract}

Key words: Pregnancy, Decidua, Feto-maternal interface, Uterine NK, Immune tolerance

\section{The endometrium is dramatically changed in function and form when getting pregnant}

In human and rodents, the endometrium can be different to the decidual cells under the influence of the steroid hormone, progesterone (Pace et al., 1989). In rodents, the non-pregnant uteri does show not any change in morphology during the estrous cycle (Fig. 1A) (Wood et al., 2007; Masuda et al., 2007; Girling et al., 2007). Under progesterone effects, the decidua basalis is formed on the mesometrium, the secondary decidual zone is formed on the anti-mesometrium and the primary decidual zone is formed to surroundings of the embryo after implantation (Fig. 1B). Additionally, the metrial gland is formed into the myometrium on the murine pregnant uterus, and offers a necessary place for angiogenesis. Interestingly, Croy B.A. et al. reported that the metrial gland has a func- tion as the lymphoid organ on the uterus during pregnancy (Bilinski et al., 2008). Actually, a lot of lymphocytes including uterine NK ( $\mathrm{uNK}$ ) cells exist in the metrial gland. The metrial gland and the decidua expand widely as the pregnancy progresses (Fig. 1C). On the decidual cells, high secretory performance is acquired from progesterone exposure. Various cytokines, growth hormones and proteases are secreted from the decidual cells under progesterone, and are constituted as an environment for maintenance of pregnancy.

\section{Immune cells}

Pregnancy is an extremely peculiar phenomenon in which growing is without rejecting the semiallogenic embryo from the maternal immune cells by intrauterine. It is clarified that the action of these hormones is the

Correspondence: Orie Nakamura (E-mail: nakamura@mch.pref.osaka.jp) 
A

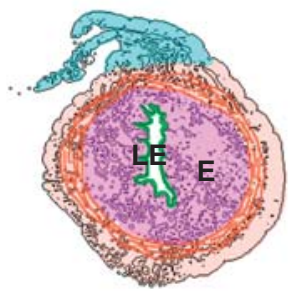

B

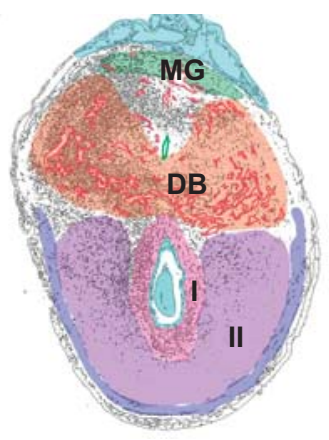

C

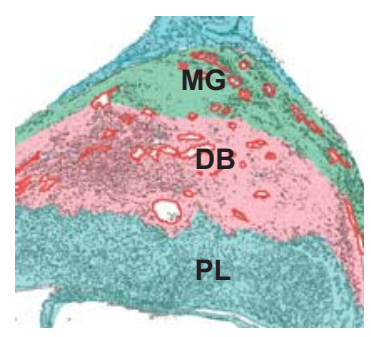

Fig. 1. Development of murine uterus during pregnancy.

Non-pregnant uterus changes in minor modification under the estrous cycle (A). After implantation, the metrial gland and the desidua basalis are formed in the mesometrial side. In D7.5 of pregnancy, embryo are surrounded with the primary decidual zone and the secondary decidual zone that will disappear later (B). In D10.5 of pregnancy, the metrial gland, the decidua and the fetal placenta, placental labyrinth are expanded (C). LE, luminal epithelium; E, endometrium; MG, metrial gland; DB, decidua basalis; I, primary decidual zone; II, secondary decidual zone; PL, placental labyrinth.

one through the cytokine and the growth factor though it had been said to be pregnancy approval and maintenance of the mammal that a hormone such as progesterone was important (Song et al., 2007; Mardon et al., 2007). These cytokines and the growth factors adjust the maintenance of pregnancy by paracrine and autocrine action in a limited part in the decidua and the labyrinthine trophoblast. Moreover, various immune cells taking part in the maintenance of pregnancy became clear in the maternal decidua. Infertility and spontaneous abortion are caused by early pregnancy when the network of the steroid hormone, the cytokines, and the maternal immune cells, and it is said that it is pregnancy-induced hypertension and intrauterine growth retardation (IUGR) at latter term (Hamai et al., 1997).

\section{T-cell immunity}

$\mathrm{CD}^{+}$helper $\mathrm{T}(\mathrm{Th})$ cells play important roles in an immune response to the antigen and adjust antibody production by B-cell and the function of cytotoxic T (Tc) cells (Aris et al., 2008). T-cell immunity is classified into Th1 immunity and Th2 immunity by the cytokine profile. During pregnancy, Th1/Th2 balance shifts to a Th2 predominant state, while other reports show that the Th1/Th2 ratio did not change in the peripheral blood during early pregnancy (Saito et al., 2007). Furthermore, both Th1 cytokine and Th2 cytokine are produced at the maternal decidua; the feto-maternal interface. However, it is certain that predominant Th2 immunity exists in early pregnant decidua, especially at the implantation site. Actually, miscarriage occurs when Leishmania major that induces the Th1 immunity to the pregnant mouse is infected
(Krishnan et al., 1996). And then, the mating of CBA/J female (H2k) mice with DBA/2J (H2d) provokes spontaneously high abortion result that Th2 cytokine including IL-4 and IL-10 are decreased in quantity in the decidua (Clark et al., 1997; Bertoja et al., 2005). IFN- $\gamma$ that is Th1 cytokine inhibit growing trophoblast cells in vitro culture system. Moreover, the cytotoxic T-cells were activated by IL-2 and induced the apoptosis of trophoblast and the fetal loss (Setiady et al., 2003). During pregnancy, the Th2 immune environments is induced by production of Th2 cytokines from decidual cells under progesterone, while the Th1 immune environment are reduced (Fig. 2). It is known that progesterone promotes surviving the tissue grafts. In the pregnant mice, PR is induced on the activated T-cells. Progesterone receptor positive activated T-cells are promoted to induce Th2 cells under progesterone, and differentiated Th2 cells produce some kind of Th2 cytokine, IL-4, 5 and IL-10 (Maccarrone et al., 2001; Raghupathy et al., 2005). Progesterone, also affects the decidual cells to produce IL-4, 5, 10 and TGF- $\beta 1$. In the presence of excess Th1 cytokine; IL-2, IL-12, TNF$\alpha$, and IFN- $\gamma$, the developments of trophoblast are rejected and fetal loss is caused (Sunder and Lenton, 2000). Oppositely, the differentiation from Th0 to Th1 and the expression of activity of NK cells are inhibited under the abundant Th2 cytokine in the maternal decidua. These predominantly $\mathrm{Th} 2$ shifts in the pregnant uterus are significantly correlated with the maintenance of pregnancy.

\section{Unique lymphocytes; uNK cells}

During human pregnancy, rodents and other species of mammals, a unique subset of lymphocytes predominates 
at the implantation site (Oh and Croy, 2008). In mice, the uterine lymphocytes called uNK cells are characterized by the large granules stained by periodic acid Schff (PAS), (Figs. 3A-C). The uNK cells differentiate in situ from bone marrow derived immature precursor cells that are small and agranular (Santoni et al., 2008). The uNK precursor cells are small and changed in number corresponding to the estrous cycle (Figs. 4A-E and I). In the pregnant uterus, uNK cells differentiate into mature cells that have large granules and are localized in the metrial gland and the decidua basalis of each placenta (Figs. 4F, G and J).

The mechanism of uNK cell differentiation is still unknown. One of the sex steroid hormones, progesterone, is suggested to have a significant function in the differentiation of uNK cells, because uNK cell development is wholly synchronized with the progesterone level. However, uNK cells do not have progesterone receptors and cannot differentiate in the pseudopregnant uterus. Therefore progesterone level is enough (Fig. 4H). Recent study reported that extracellular matrix (ECM) takes part in differentiation of uNK cells. Kiso et al. $(1992,1997)$ showed the differentiation and distribution pattern of uNK cells in the tight-skin (Tsk/+) mice and the alymphoplasia (aly/ aly) mice. Tsk/+ mice produce excess collagens I and III. uNK cells could differentiate in pregnant Tsk/+ female, but the distribution pattern was abnormal. On the other hand, aly/aly mice are considered to be a useful model for the study of interactions between lymphocytes and stromal components, since they are genetically deficient in lymph nodes and Peyer's patches due to a lymphoid-associated mesenchymal disorder. The immunodeficiency of

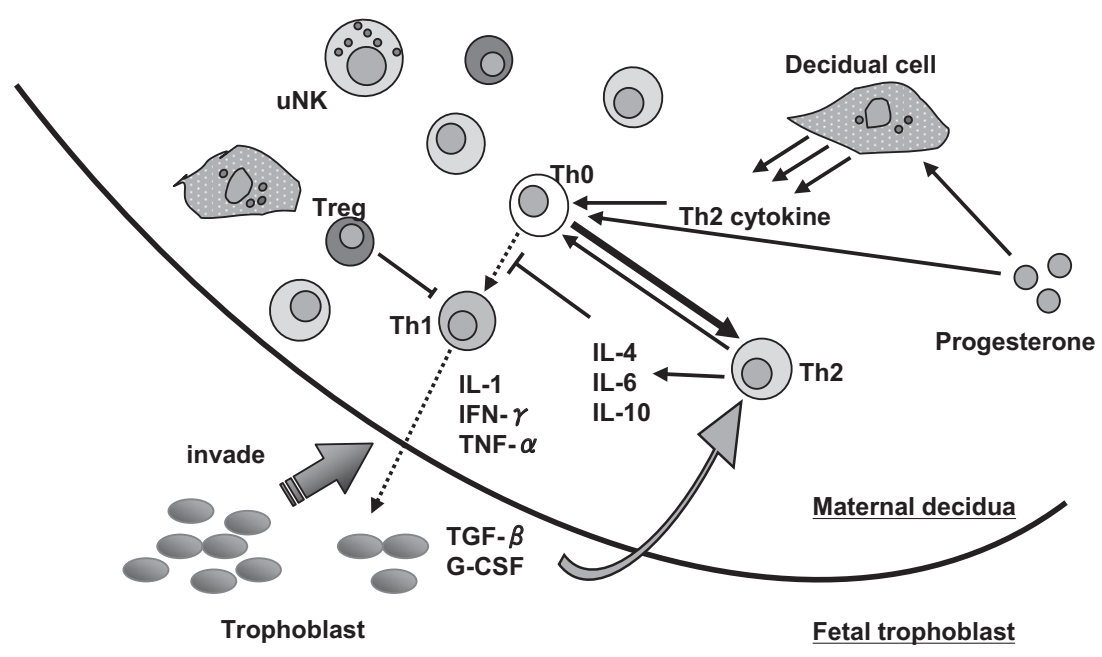

Fig. 2. Th1/Th2 paradigm in the maternal decidua. The immune environment of predominant Th2 cells is maintained by the cooperation of the decidua and the Th2 cytokine for the maintenance of pregnancy under progesterone existence.
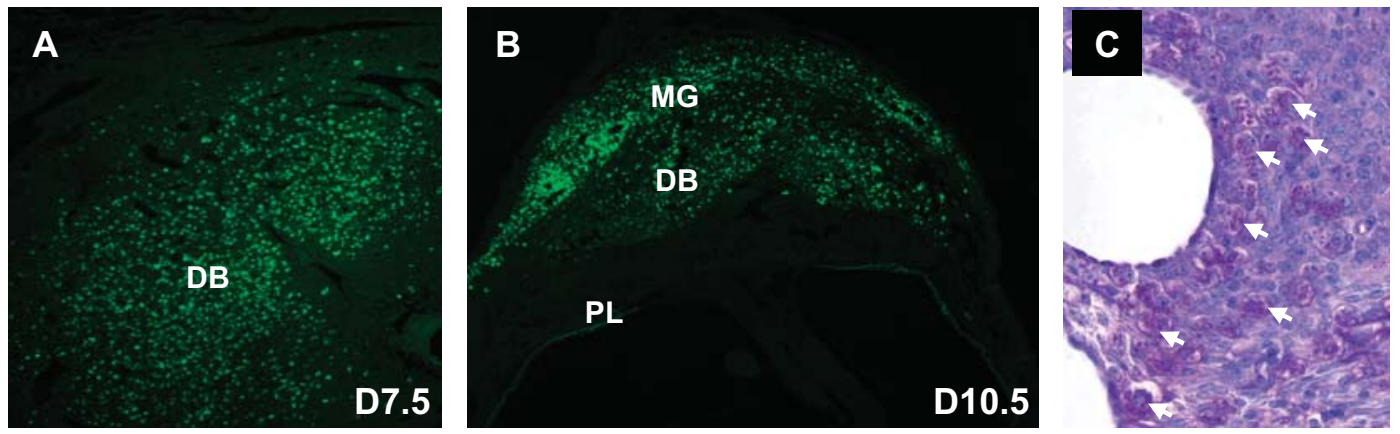

Fig. 3. Immunofluorescent, after DBA lectin stain, of murine uterus on D7.5 (A) and D10.5 (B) of pregnancy. uNK cells appeared in DB and MG. Large granules of uNK cells (arrows) are detected by PAS stain (C). MG, metrial gland; DB, decidua basalis; PL, placental labyrinth. 

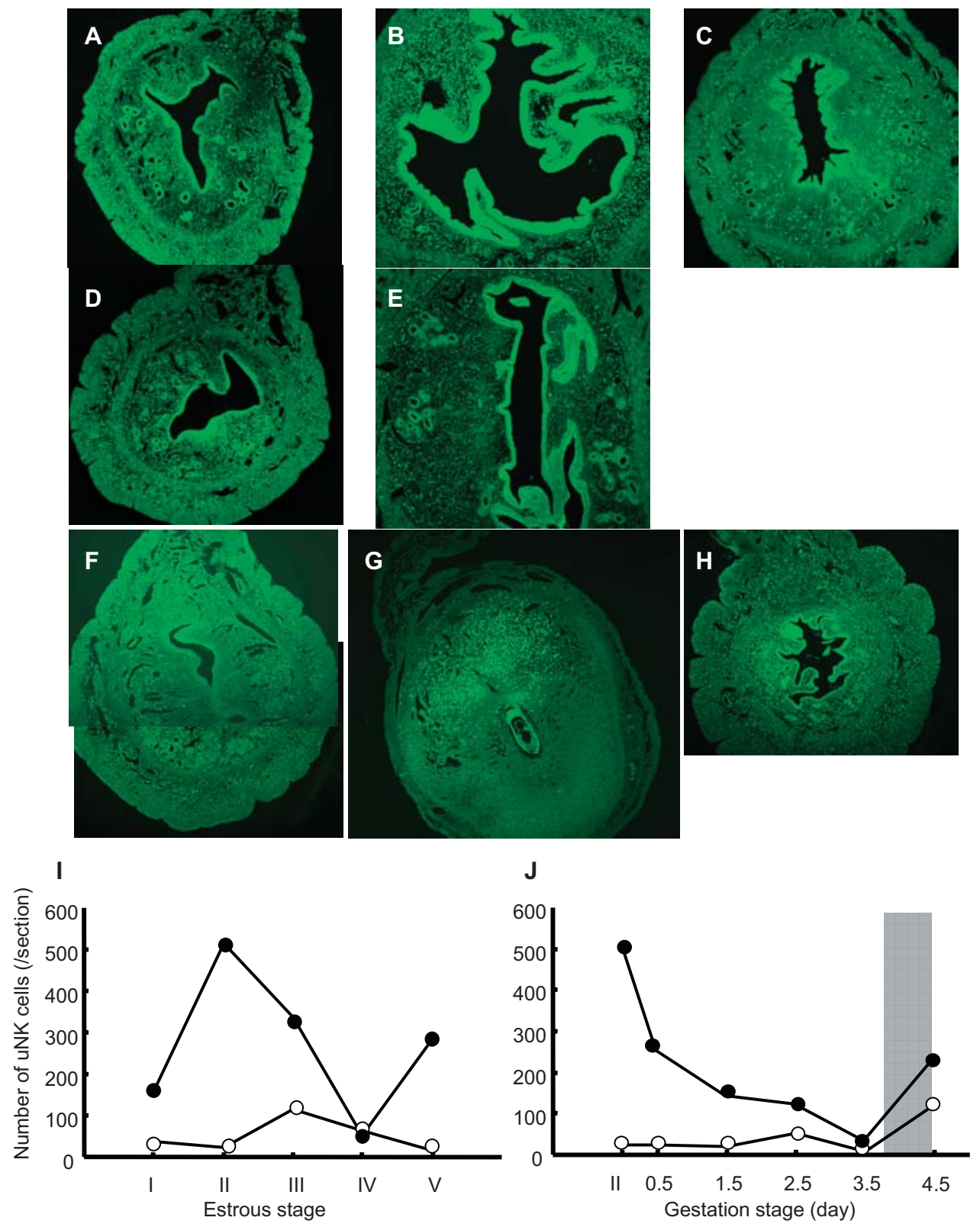

Fig. 4. uNK populations of non-pregnant and pregnant uterus. In non-pregnant uterus, the numbers of uNK cells are changed as interacted with estrous cycle stages (A, stage I, proestrus; B, stage II, early estrus; C, stage III, estrus; D, stage IV, metaestrus; $\mathrm{E}$, stage $\mathrm{V}$, diestrus). uNK cells increased in number on stage II (B, I). In pregnant uterus, uNK cells decreased in number forward to D3.5 of pregnancy, but increased in number again on D4.5 of pregnancy (F, J). It differs from D7.5 of pregnancy $(\mathrm{G})$, and the uNK cells are hardly seen in D7.5 of pseudopregnancy $(\mathrm{H})$, although progesterone is even enough. Closed circles show uNK in endometrium, open circle show uNK in myometrium. Gray zone of $\mathrm{J}$ is the implantation period.

aly/aly mice results from an abnormality in the microenvironment of its various lymphoid tissues. The interaction between homing receptors on lymphocytes with ligands on endothelial cells has been suggested as a possible deficit. Metrial gland tissue was present and appeared nor- mal in aly/aly mice. The distribution of uNK cells from aly/+ mice was normal. Fewer uNK cells were present in aly/aly mice than aly/+ mice and the features of individual uNK cells were different; i.e., uNK cells in aly/ aly mice were small in size and the granules were poorly 
Immune system during pregnancy

developed. In vitro culture system showed that uNK cells reacted with various proteins of ECM components and indicated different reaction of $\mathrm{uNK}$ cells. The expressions of ECM receptors on uNK cells were evaluated immunohistochemically at various stages of pregnancy using anti-very late antigen (VLA)-integrin antibodies (Kiso et al., 1994). Immature uNK cells were positive for VLA$\alpha 1$, VLA- $\alpha 3$ (collagen/laminin receptor), VLA- $\alpha 4$, VLA$\alpha 5$ (fibronectin receptor) and VLA- $\alpha 6$ (laminin receptor) chains. Otherwise, mature uNK cells were positive for VLA- $\alpha 4$, VLA- $\alpha 5$ chains only. These results are significantly correlated with the laminin decreases and the fibronectin increases in the pregnant decidua. Recent studies revealed that $\mathrm{uNK}$ cells express the estrogen receptor (ER) $\beta 1$ only, and therefore express nether PR nor ER $\alpha 1$, and is not the relationship between these steroid receptors and success of pregnancy (Arruvito et al., 2008). The experiment of differentiation of murine uNK cells in the ectopically grafted uterine tissues showed that the decidualization of the endometrium is necessary for the differentiation of uNK cells, but the other factors that have direct effect to the uNK cells remain unknown. IL-15 secreted from the decidua under progesterone is ligand for IL-15 receptor that is composed of the specific alpha chain, beta chain and gamma chain. Because of the beta and gamma chains are the same as IL-2 receptor, the biological activity induced by IL-15 becomes similar to one induced by IL-2. Therefore, the analysis of IL-15 KO mice suggests that IL-15 is participated in the differentiation of uNK cells (Kitaya et al., 2005). The immunological func- tion of uNK cells is still unknown, but uNK cells are correlated with the angiogenesis in the decidua by production of angiogenesis factors. TgE26 mice are transgenic mice overexpressing human CD3egene. This transgenic mice defects T-cells and peripheral NK cells, and more uNK cells. Pregnancy in TgE26 mice was characterized by very small placenta (half size of control), poor development of the metrial gland and infrequency of uNK cells (Guimond et al., 1996, 1997; Hunt et al., 1997). In TgE26 mice, a sudden onset of fetal loss began at day12-14 of pregnancy. Such fetal death was associated with progressive changes in the maternal uterine arterioles, suggesting localized hypertension. SCID mice have a feature of the T-cell and B-cell deficiency. To confirm the role of uNK cells during pregnancy, the bone marrow from SCID mice were transplanted to TgE26 females (Guimond et al., 1998). Engrafted pregnant female mice have recovery of the uNK cell population, induce metrial gland differentiation, reduced anomalies in decidua and decidual blood vessels, increased placental size, and restoration of fetal viability. These clearly indicated that uNK cells have critical function in pregnancy that promotes decidual health, the appropriate vascularization on implantation sites, and placental size. In the murine pregnant uterus, extravillous cytotorophoblast has invaded the maternal decidua. When the decidual macrophage or dendritic cells recognize the trophoblast debris, uNK cells may become active and acquire a cytotoxic function the same as the peripheral NK cells (Fig. 5).

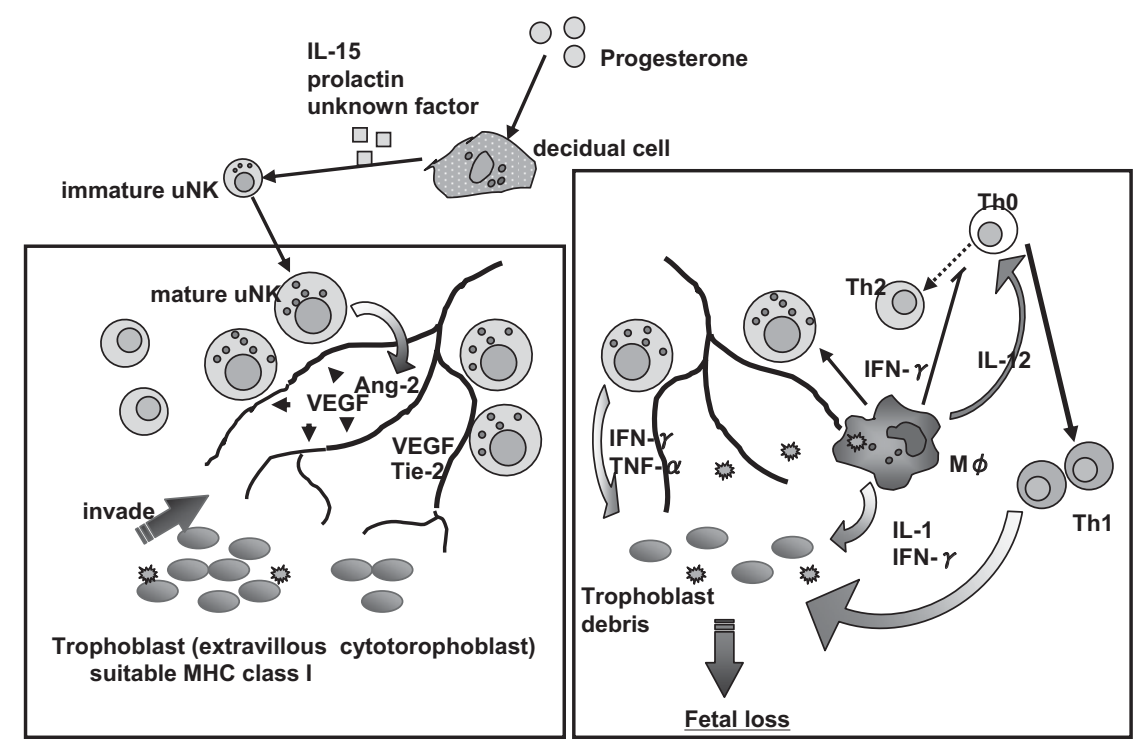

Fig. 5. Function of uNK cells in the maternal decidua. Mature uNK cells produce some angiogenic factors during normal pregnancy (left square), whereas uNK cells produce cytolytic factors in the abortion site (right square). 


\section{IGF-I overexpression effect on abnormal differentiation of uNK cells}

Various cytokines and growth factors are produced in the decidua under progesterone, and participate in the maintenance of pregnancy. IGF-I is assumed to appear by the endometrium in the implantation period, and for a fetal development and important relations to exist though information on the function of IGF-I in the decidua is slight. Between D5 and D6 of pregnancy, there is a rapid induction of IGF-I mRNA in uterine stromal cells underlying the myometrium (Han and Carter, 2000). IGF-I has metabolic, mitogenic and differentiative actions in fetal tissues and the placenta (Jones and Clemmons, 1995). These results suggest that IGF-I plays a role in differentiation of the endometrial stroma cells to the decidual cells. We found that IGF-I overexpression caused fetal loss in pregnant mice, and that uNK cells looked unusual in the placenta with fetal loss. On D3.5 of pregnancy, mice were transfected IGF-I cDNA using injection into the left uterine horn and sacrificed on D7.5, D10.5, D12.5, and D15.5 of pregnancy. Fetal loss was observed in mice uteri that had overexpessed IGF-I on the pregnant uteri. The fetal loss occurred with the progress of pregnancy (Fig. 6). In the untransfected uterine horn (right side), fetal loss was not observed and the remaining fetuses developed normally. On D7.5 of pregnancy, there were scarcely abortion sites but each implantation site was larger in size in the transfected horn than the untransfected horn (Fig. 6A). On D10.5-15.5 of pregnancy, the embryos on the transfected site died and, were absorbed into the maternal uterine tissues (Figs. 6B and C). Histological change in the IGF-I transfected uterine horn showed abnormal decidualization and abnormal prolongation of uNK viability. In the transfected site on D12.5 of pregnancy, the decidua basalis was thickened and blood vessels in the decidua were expanded (Fig. 7A). However, the placenta looked healthy, i.e., the placenta constituted of the metrial gland, the decidua basalis and the labylinthin zone (Figs. 7B and C). uNK cells displayed a prolongation of viability suggesting that the inhibition of apoptosis which showed on the normal pregnant uterus (Fig. 8). These results may suggest that angiogenesis in the decidua by induction of abnormal uNK cells kept for a longer time than usually (Fig. 9). It is important that it doesn't depend
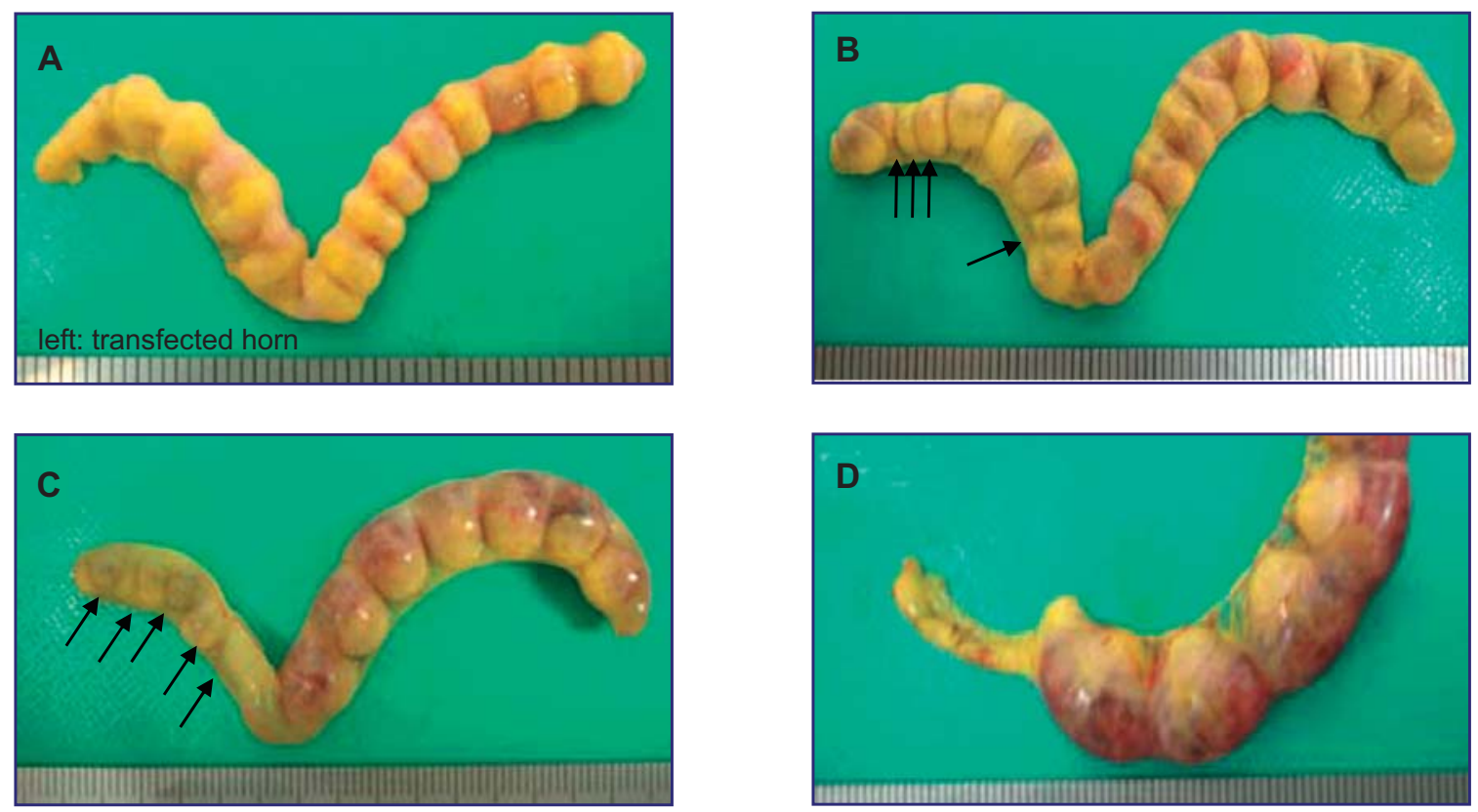

Fig. 6. Pregnant uteri from IGF-I overexpressed mice. On D7.5 of pregnancy, each implantation site was larger in size in the transfected uterine horn (left side) than the untransfected horn, and fetal loss is not observed (A). On D10.5 of pregnancy, some abortion sites (arrows) could be seen in the transfected horn (B). On D12.5 of pregnancy, most of the embryos were dead in the transfected horn (arrows), while healthy embryos developed in the untransfected site (C). On D15.5 of pregnancy, all of the embryos were absorbed in the transfected horn, while healthy embryo were developed more in the untransfected site (D). 

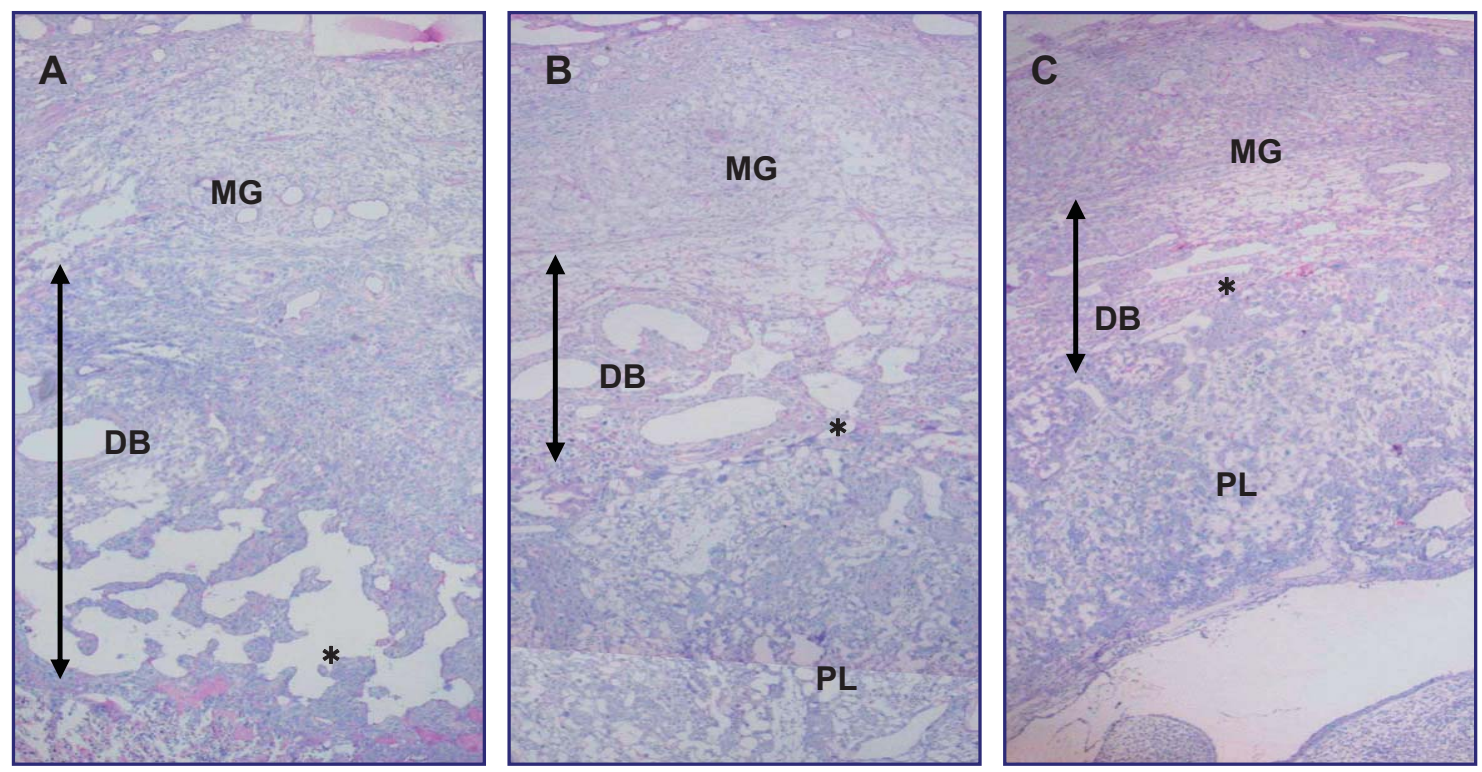

Fig. 7. Histology of the transfected, untransfected and intact uteri on D12.5 of pregnancy. The decidua basalis increased in thickness, and the vascular lumen $(*)$ was expanded in the transfected uterus (A). No change was observed in the untransfected uterus (B) same as intact uterus (C). MG, metrial gland; DB, decidua basalis; PL, placental labyrinth.
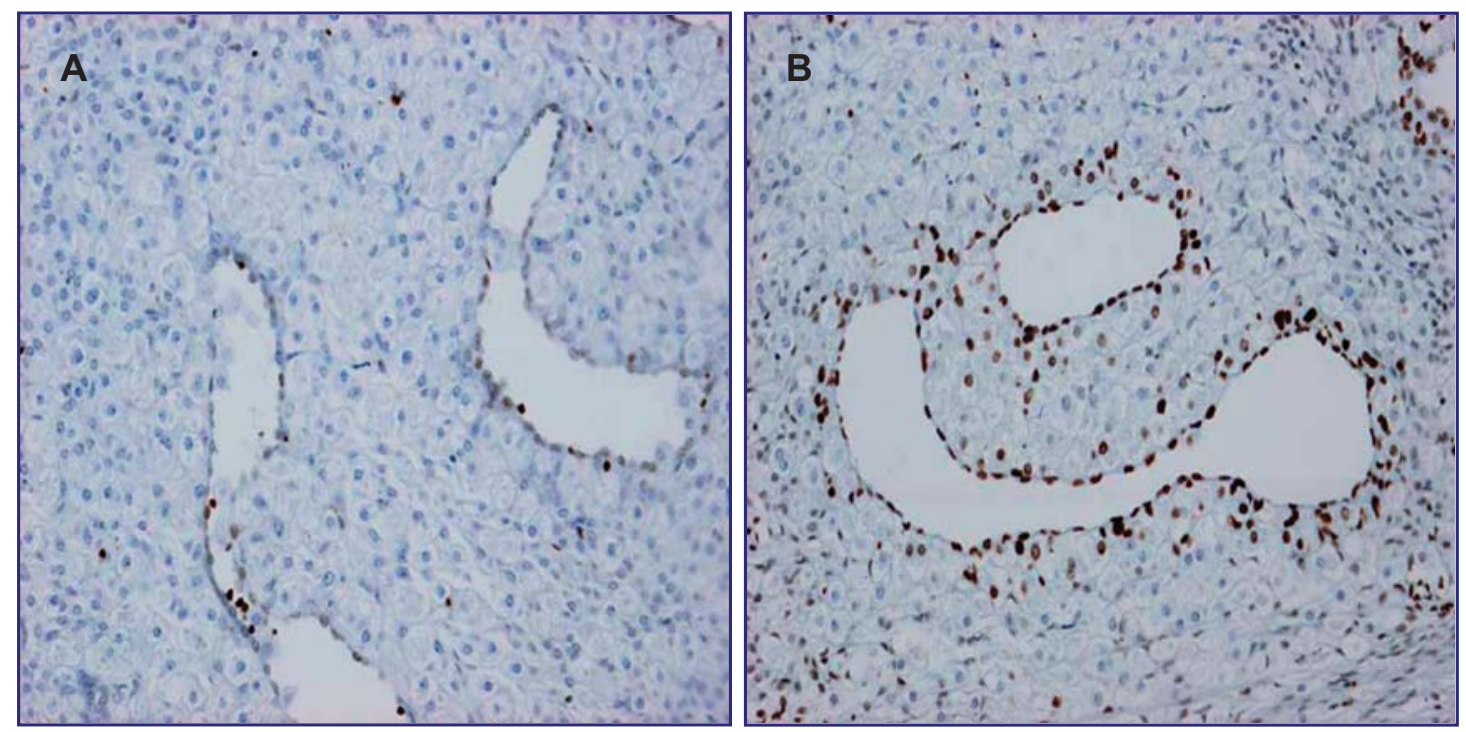

Fig. 8. Detection of apoptotic cells in the maternal decidua on D13.5 of pregnancy. Most uNK cells were negative for anti-ssDNA in the transfected uterus (A), whereas a lot of uNK cells were positive for anti-ssDNA in the untransfected uterus (B). 


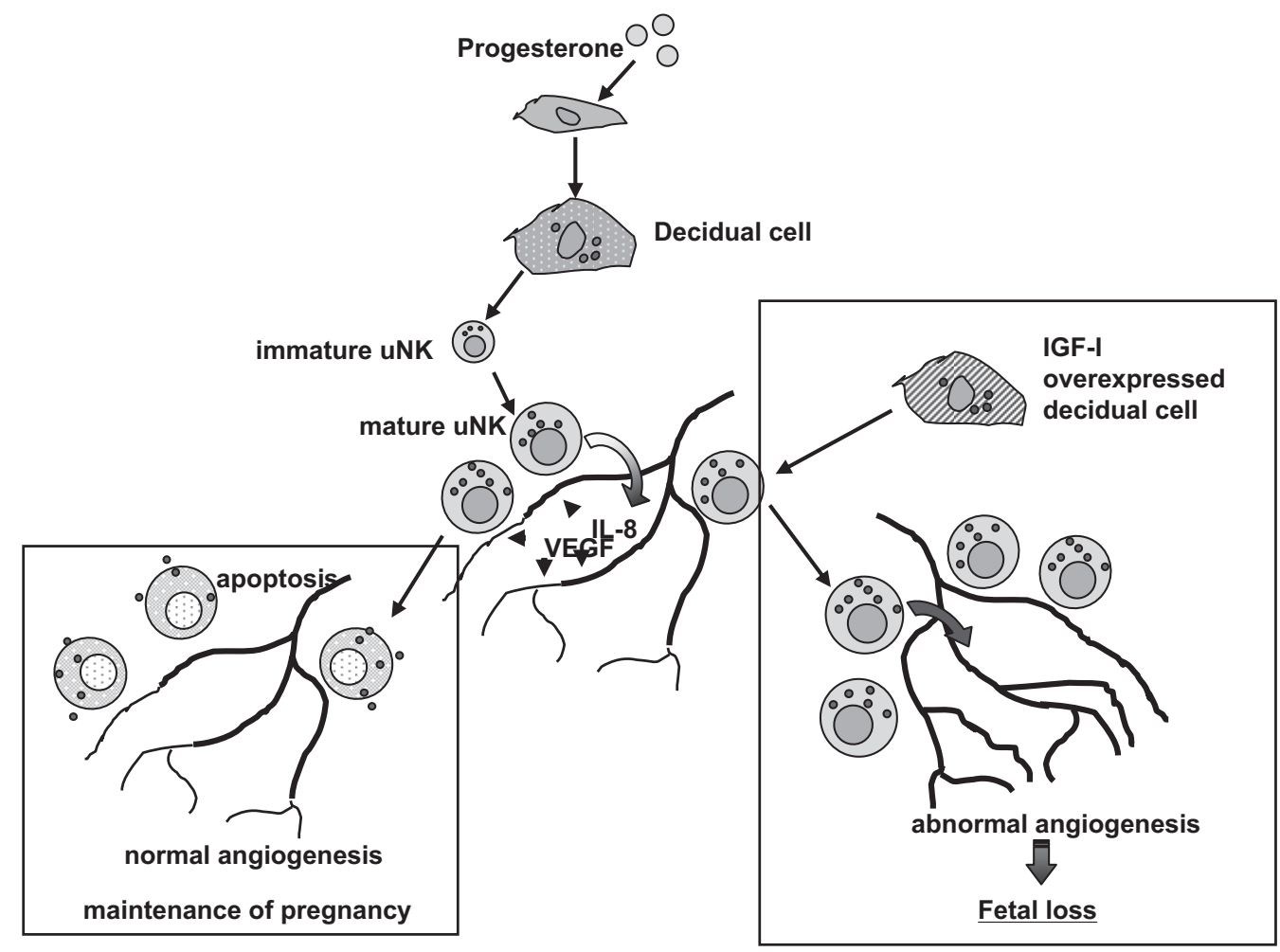

Fig. 9. Function of uNK cells may show enhancement but apoptosis dose not occur in the decidua in the IGF-I overexpressed mice. In abnormal decidua, angiogenesis might continue longer than usually by uNK cells resulting that fetal loss occurred (right square).

on the normal development of fetus alone but the function of maternal placenta correctly to success in pregnancy. The balance of the immune cells that is appropriate for the pregnancy is delicately adjusted by the interaction with the functional decidual cells, and protects the development of the fetus.

\section{ACKNOWLEDGMENT}

This peer-reviewed article is based upon a lecture presented at the 35th Annual Meeting of Japanese Society of Toxicology, June 2008 in Tokyo under the theme of "Children's Toxicology", June 2008 in Tokyo.

\section{REFERENCES}

Aris, A., Lambert, F., Bessette, P. and Moutquin, J.M. (2008): Maternal circulating interferon-gamma and interleukin- 6 as biomarkers of Th1/Th2 immune status throughout pregnancy. J. Obstet. Gynaecol. Res., 34, 7-11.

Arruvito, L., Giulianelli, S., Flores, A.C., Paladino, N., Barboza, M.,
Lanari, C. and Fainboim, L. (2008): NK cells expressing a progesterone receptor are susceptible to progesterone-induced apoptosis. J. Immunol., 180, 5746-5753.

Bertoja, A.Z., Zenclussen, M.L., Casalis, P.A., Sollwedel, A., Schumacher, A., Woiciechowsky, C., Volk, H.D. and Zenclussen, A.C. (2005): Anti-P- and E-selectin therapy prevents abortion in the $\mathrm{CBA} / \mathrm{J} \times \mathrm{DBA} / 2 \mathrm{~J}$ combination by blocking the migration of Th1 lymphocytes into the foetal-maternal interface. Cell. Immunol., 238, 97-102.

Bilinski, M.J., Thorne, J.G., Oh, M.J., Leonard, S., Murrant, C., Tayade C. and Croy, B.A. (2008): Uterine NK cells in murine pregnancy. Reprod. Biomed. Online, 16, 218-226.

Clark, D.A., Merali, F.S., Hoskin, D.W., Steel-Norwood, D., Arck, P.C., Croitoru, K., Murgita, R.A. and Hirte, H. (1997): Decidua-associated suppressor cells in abortion-prone DBA/2-mated $\mathrm{CBA} / \mathrm{J}$ mice that release bioactive transforming growth factor beta2-related immunosuppressive molecules express a bone marrow-derived natural suppressor cell marker and gamma delta T-cell receptor. Biol. Reprod., 56, 1351-1360.

Girling, J.E., Lederman, F.L., Walter, L.M. and Rogers, P.A. (2007): Progesterone, but not estrogen, stimulates vessel maturation in the mouse endometrium. Endocrinology, 148, 5433-5441.

Guimond, M.J., Luross, J.A., Wang, B., Terhorst, C., Danial, S. and Croy, B.A. (1997): Absence of natural killer cells during murine pregnancy is associated with reproductive compromise in TgE26 
Immune system during pregnancy

mice. Biol. Reprod., 56, 169-179.

Guimond, M.J., Wang, B. and Croy, B.A. (1998): Engraftment of bone marrow from severe combined immunodeficient (SCID) mice reverses the reproductive deficits in natural killer cell-deficient tg epsilon 26 mice. J. Exp. Med., 187, 217-223.

Guimond, M.J., Wang, B., Fujita, J., Terhorst, C. and Croy, B.A (1996): Pregnancy-associated uterine granulated metrial gland cells in mutant and transgenic mice. Am. J. Reprod. Immunol., 35, 501-509.

Hamai, Y., Fujii, T., Yamashita, T., Kozuma, S., Okai, T. and Taketani, Y. (1997): Pathogenetic implication of interleukin2 expressed in preeclamptic decidual tissues: a possible mechanism of deranged vasculature of the placenta associated with preeclampsia. Am. J. Reprod. Immunol., 38, 83-88.

Han, V.K. and Carter, A.M. (2000): Spatial and temporal patterns of expression of messenger RNA for insulin-like growth factors and their binding proteins in the placenta of man and laboratory animals. Placenta, 21, 289-305.

Hunt, J.S., Miller, L., Vassmer, D. and Croy, B.A. (1997): Expression of the inducible nitric oxide synthase gene in mouse uterine leukocytes and potential relationships with uterine function during pregnancy. Biol. Reprod., 57, 827-836.

Jones, J.I. and Clemmons, D.R. (1995): Insulin-like growth factors and their binding proteins: biological actions. Endocr. Rev., 16, 3-34.

Kiso, Y., Kusakabe, K., Tokunaga, Y., Makita, M., Okada, T. and Sasaki, F. (1997): A study of granulated metrial gland cells in the pregnant, alymphoplasia (aly/aly) mice. J. Vet. Med. Sci., 59, 1137-1141

Kiso, Y., McBey, B.A. and Croy, B.A. (1992): Granulated metria gland cells in the pregnant uterus of mice expressing the collagen mutation tight-skin (Tsk/+). Cell Tissue Res., 268, 393-396.

Kiso, Y., Yoshizawa, M., Wilson, J.A., McBey, B.A. and Croy, B.A. (1994): Immunohistochemical analysis of beta 1-integrin receptors displayed by murine uterine natural killer cells over the course of successful pregnancy. J. Reprod. Immunol., 27, 213225.

Kitaya, K., Yamaguchi, T. and Honjo, H. (2005): Central role of interleukin-15 in postovulatory recruitment of peripheral blood CD16(-) natural killer cells into human endometrium. J. Clin. Endocrinol. Metab., 90, 2932-2940.

Krishnan, L., Guilbert, L.J. and Russell, A.S. (1996): Wegmann TG, Mosmann TR, Belosevic M. Pregnancy impairs resistance of $\mathrm{C} 57 \mathrm{BL} / 6$ mice to Leishmania major infection and causes decreased antigen-specific IFN-gamma response and increased production of T helper 2 cytokines. J. Immunol., 156, 644-652.

Maccarrone, M., Valensise, H., Bari, M., Lazzarin, N., Romanini, C. and Finazzi-Agrò, A. (2001): Progesterone up-regulates anandamide hydrolase in human lymphocytes: role of cytokines and implications for fertility. J. Immunol., 166, 7183-7189.

Mardon, H.J., Bagchi, M.K., Bagchi, I.C., Peng, C., Karpovich, N. and Wang, Y. (2007): Hormonal and paracrine regulation of embryonic implantation: a workshop report. Placenta, 28 (Suppl. A), S82-S84.

Masuda, H., Kalka, C., Takahashi, T., Yoshida, M., Wada, M., Kobori, M., Itoh, R., Iwaguro, H., Eguchi, M., Iwami, Y., Tanaka, R., Nakagawa, Y., Sugimoto, A., Ninomiya, S., Hayashi, S., Kato, S. and Asahara, T. (2007): Estrogen-mediated endothelial progenitor cell biology and kinetics for physiological postnatal vasculogenesis. Circ. Res., 101, 598-606.

Oh, M.J. and Croy, B.A. (2008): A map of relationships between uterine natural killer cells and progesterone receptor expressing cells during mouse pregnancy. Placenta, 29, 317-323.

Pace, D., Morrison, L. and Bulmer, J.N. (1989): Proliferative activity in endometrial stromal granulocytes throughout menstrual cycle and early pregnancy. J. Clin. Pathol., 42, 35-39.

Raghupathy, R., Al Mutawa, E., Makhseed, M., Azizieh, F. and Szekeres-Bartho, J. (2005): Modulation of cytokine production by dydrogesterone in lymphocytes from women with recurrent miscarriage. BJOG, 112, 1096-1101. Erratum in: BJOG, 112, 1585.

Saito, S., Shiozaki, A., Sasaki, Y., Nakashima, A., Shima, T. and Ito, M. (2007): Regulatory T cells and regulatory natural killer (NK) cells play important roles in feto-maternal tolerance. Semin. Immunopathol., 29, 115-122.

Santoni, A., Carlino, C. and Gismondi, A. (2008): Uterine NK cell development, migration and function. Reprod. Biomed. Online, 16, 202-210.

Setiady, Y.Y., Samy, E.T. and Tung, K.S. (2003): Maternal autoantibody triggers de novo $\mathrm{T}$ cell-mediated neonatal autoimmune disease. J. Immunol., 170, 4656-4664.

Song, H., Han, K. and Lim, H. (2007): Progesterone supplementation extends uterine receptivity for blastocyst implantation in mice. Reproduction., 133, 487-493.

Sunder, S. and Lenton, E.A. (2000): Endocrinology of the periimplantation period. Baillieres Best Pract. Res. Clin. Obstet. Gynaecol., 14, 789-800.

Wood, G.A., Fata, J.E., Watson, K.L. and Khokha, R. (2007): Circulating hormones and estrous stage predict cellular and stromal remodeling in murine uterus. Reproduction, 133, 1035-1044. 
